\title{
Model of a new joint thread for a drilling tool and its stress analysis used in a slim borehole
}

\author{
Yu Wang ${ }^{1,2}$, Bairu Xia ${ }^{1,2}$, Zhiqiao Wang ${ }^{1,2}$, and Chong Chai ${ }^{1,2}$ \\ ${ }^{1}$ School of Engineering and Technology, China University of Geosciences, 100083 Beijing, China \\ ${ }^{2}$ Key Laboratory on Deep Geo-Drilling Technology of the Ministry of Land and Resources, China University \\ of Geosciences, 100083 Beijing, China \\ Correspondence to: Zhiqiao Wang (zqwang@cugb.edu.cn)
}

Received: 3 April 2016 - Revised: 16 June 2016 - Accepted: 6 July 2016 - Published: 31 August 2016

\begin{abstract}
The drilling pipe used in slim-borehole drilling performs well due to its low cost and high efficiency. Good sealing properties and coupling strength are the two keys to ensure that the pipe works correctly. In this paper, a $68 \mathrm{~mm}$ diameter drilling pipe and its joint are developed. On the basis of Lame's theory, the contact model of the joint thread is represented under different axial force, makeup torque, and pressure difference between inner and outer pipe. This model provides a good reference for judging the quality of sealing of the joint thread. The analysis software ANSYS $\backslash$ Workbench is applied to stimulate the distribution of contact stress and sealing properties. A premium condition for drilling has been proposed, which provides a good theoretical basis for slim-borehole drilling.
\end{abstract}

\section{Introduction}

The drilling pipe used in slim-borehole drilling performs well due to its lower cost and higher efficiency (Zhang et al., 2015). Due to it being the most fragile component of the whole driving pipe string (Zhou, 2009), the joint thread has attracted many researchers' interest to improve its sealing quality (Li et al., 2014) and connection stress, which are the key characteristics and areas of research emphasis with regard to the drilling pipe (Gong, 1995).

Many studies have been conducted on the joint thread according to American Petroleum Institute (API) standards (American Petroleum Institute, 1995). Tafreshi and Dover (1993) analysed threaded connections using a finiteelement method (FEM) to find the greatest concentration of stress under the action of axial loading. However, the contact stress was not reported. They optimized the shape of the teeth of the threaded connection according to the load distribution. Baryshnikov and Baragetti (2001) determined the load bearing percentage of each tooth to calculate allowable loads for API drill string threaded connections under conditions of bending and axial and combined loading. Griffin et al. (2004) analysed the stresses in a specific drill pipe connection under axial loading via FEM. Shahani and Sharifi (2009) built a model contact between mating surfaces of the threads and analysed this by using ABAQUS 6.6 standard code. The contact pressure on the contact surfaces and the effect of preload on the stress concentration factor and were investigated. Santus et al. (2009) compared the torsional strength between two assembling techniques for connection of an aluminium drill pipe to a steel tool joint. Zhang et al. (2010) studied the taper trapezium joint threads of a drilling rod with a large hole. An improvement scheme for dual taper and cylinder seal has been proposed which has successfully tackled the problem of stress concentration. A double-sealing shoulder was used by $\mathrm{Li}$ et al. (2011) to develop a $73 \mathrm{~mm}$ diameter directly connected drill pipe without friction welding. The angular clearance was enlarged, which can satisfy the logging tool and drill-out tool. Zhu et al. (2013) established a drill pipe thread FEM to aid failure analysis and to study solutions in a horizontal-direction drilling project. An XT-M joint developed by Grant Prideco has reached a high level of technology. Its torsional capability is $70 \%$ higher than the API's, whose joint airtight capacity can reach 15000 psi (Zhuang et al., 2015). 

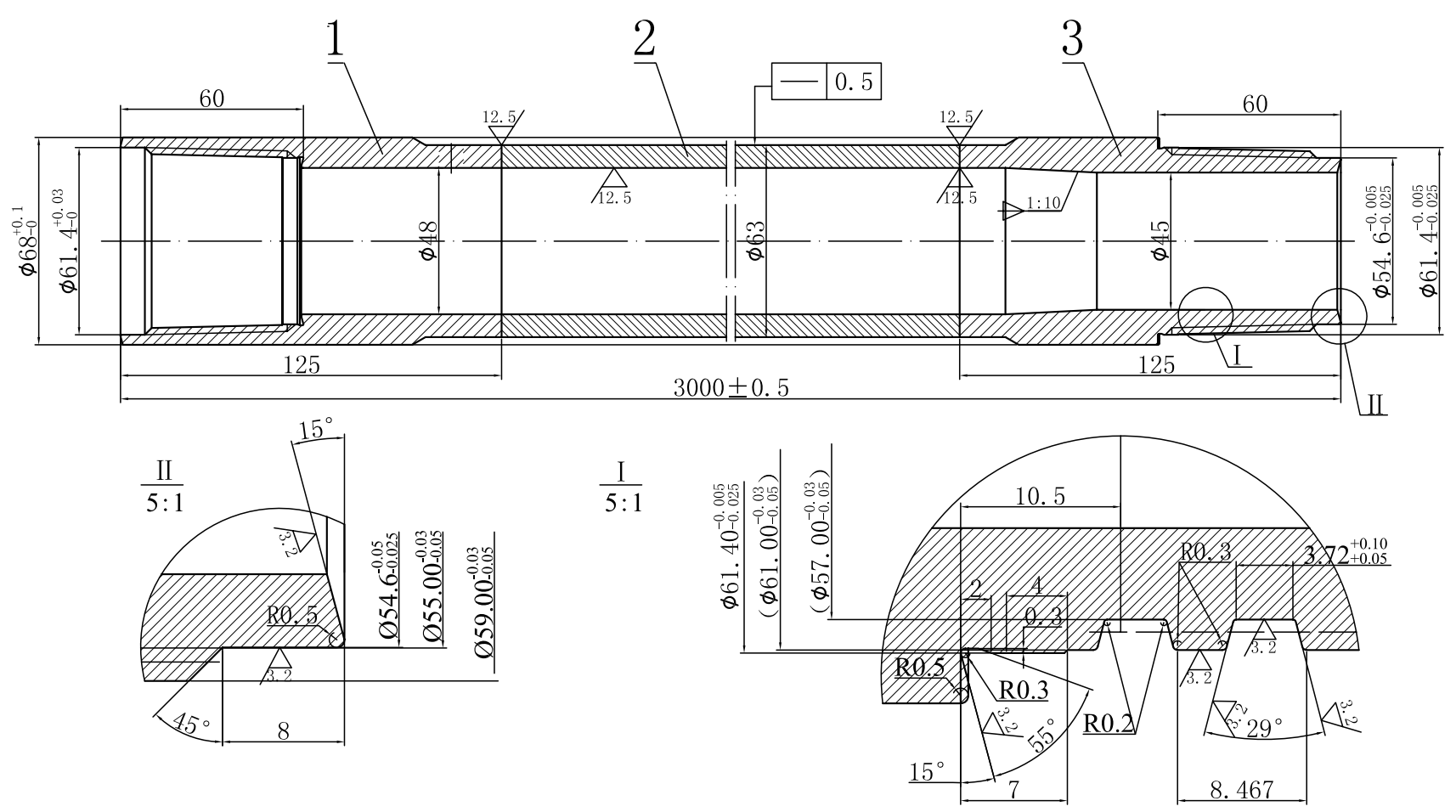

Figure 1. Structure of the drilling pipe.

The contact model of the drill pipe has been analysed, and different specifications of the thread have been designed, but these connections are used in a large-sized oil well. Few studies have been conducted with regard to modelling the correlation between the contact stress and tightness. At present, most of the drill pipes which are widely used in API standard are more than $89 \mathrm{~mm}$ in diameter (Shi et al., 2014; Wang et al., 2010). API seldom performs research on small-diameter drill pipes, as these are unable to meet the requirements of slim-borehole drilling.

In this paper, a $68 \mathrm{~mm}$ diameter drilling pipe and its joint are developed. On the basis of Lame's theory, we create a contact model of the joint thread under different axial force, makeup torque, and pressure difference between inner and outer pipe, which provides a good reference for judging the quality of sealing of the joint thread. The analysis software ANSYS $\backslash$ Workbench is applied to stimulate the distribution of contact stress and sealing. A premium condition for drilling has been proposed, which provides a good theoretical basis for slim-borehole drilling.

\section{Model of the tool joint}

\subsection{Structure of the drilling pipe}

Based on the requirements of a slim-borehole drill, the drill pipe is designed as shown in Fig. 1. The drill pipe consists of pin joint 3 , box joint 1 and drilling pipe body 2 . The joint

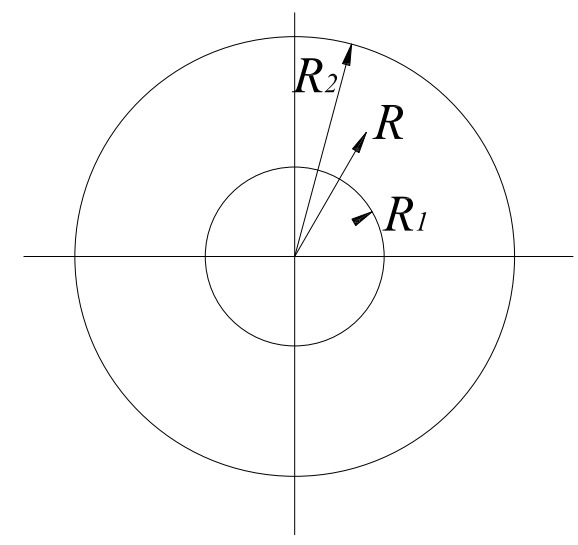

Figure 2. Basic model of the joint for stress analysis.

is connected to the pipe body by friction welding. The joints are connected to the pipe body by friction welding and stressrelieving annealing. The concentricity between the joints and pipe body is no greater than $0.4 \mathrm{~mm}$. There is a flat surface inside and outside the welding position, whose faults are eliminated. The connector is the cone threaded joint, with a 1:30 thread taper and equilateral trapezoid thread. The overall quenching hardness can be equal to the hardness of HRC30-35. The sealing cone concentricity of the respective internal and external threads is no greater than $0.02 \mathrm{~mm}$. The end portion of the incomplete thread is cut off. 


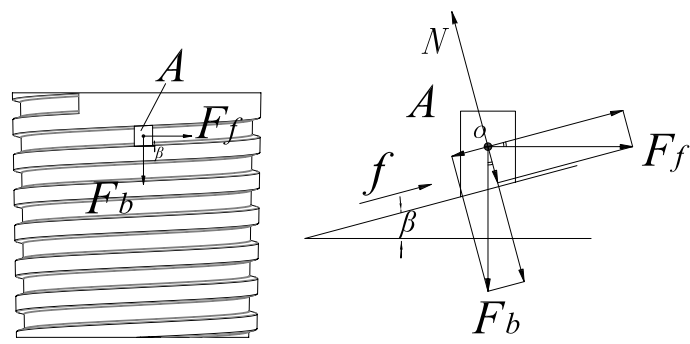

Figure 3. Force diagram of thread $A$.

\subsection{Theoretical foundation and assumptions}

The thread is the most fragile but important component in the pipe. According to the theory of thread sealing, the thread's sealing is realized through the interference fit between the thread's teeth. The sealing quality is mainly influenced by the stress of the connection of the joint thread, which has a close relationship between axial load, makeup torque, and the pressure difference between inner and outer pipe.

The projection of the drill pipe joints at one certain point in the radial direction is a thick-walled cylinder. Based on the analysis method of Lame's stress, as shown in Fig. 2, the radial stress and circumferential stress of some certain point under mud pressure within the drill pipe are expressed as

$$
\left\{\begin{array}{c}
\sigma_{\mathrm{r}}=\frac{R_{1}^{2} \cdot P_{\mathrm{i}}}{R_{2}^{2}-R_{1}^{2}} \cdot\left(1-\frac{R_{2}^{2}}{R^{2}}\right) \\
\sigma_{t}=\frac{R_{1}^{2} \cdot P_{\mathrm{i}}}{R_{2}^{2}-R_{1}^{2}} \cdot\left(1+\frac{R_{2}^{2}}{R^{2}}\right)
\end{array} .\right.
$$

Likewise, the radial stress and circumferential stress under the mud pressure outside the drill pipe are

$$
\left\{\begin{array}{c}
\sigma_{\mathrm{r}}=\frac{R_{2}^{2} \cdot P_{e}}{R_{2}^{2}-R_{1}^{2}} \cdot\left(1-\frac{R_{1}^{2}}{R^{2}}\right) \\
\sigma_{t}=\frac{R_{2}^{2} \cdot P_{e}}{R_{2}^{2}-R_{1}^{2}} \cdot\left(1+\frac{R_{1}^{2}}{R^{2}}\right) .
\end{array}\right.
$$

According to Lame's theory, the radial displacement at any point with a radius of $R$ can be expressed as

$$
u=\frac{1-\mu}{E} \cdot \frac{R\left(R_{1}^{2} P_{\mathrm{i}}-R_{2}^{2} P_{e}\right)}{R_{2}^{2}-R_{1}^{2}}+\frac{1+\mu}{E} \cdot \frac{R_{1}^{2} R_{2}^{2}\left(P_{\mathrm{i}}-P_{e}\right)}{R\left(R_{2}^{2}-R_{1}^{2}\right)} .
$$

\subsection{Contact mechanical model}

\subsubsection{Makeup torque influenced by the axial force}

A drilling string formed by a pipe connection will be influenced by different axial forces when in use - for example, gravity, drilling pressure, and friction between the pipe and the borehole wall. The force diagram of the screw thread is shown in Fig. 3. Thread $A$, intercepted from the box connector, is selected to make a mechanical analysis. Due to the spiral structure, the axial force will be decomposed, resulting in the box connector thread being subjected to, for example, the action of tangential forces and friction of the threaded surface.

Force analysis on a section of box thread $A$, and according to the balance of force conditions, can be expressed as

$$
\left\{\begin{array}{l}
f=\mu \cdot N=\mu \cdot\left(F_{\mathrm{f}} \sin \beta+F_{b} \cos \beta\right) \\
F_{\mathrm{f}} \cos \beta+F_{b} \sin \beta=f
\end{array} .\right.
$$

To finish the above formulas, the tangential force $F_{\mathrm{f}}$ can be obtained because of the axial force,

$$
F_{\mathrm{f}}=\frac{\mu \cos \beta+\sin \beta}{\cos \beta-\mu \sin \beta} \cdot F_{b}=K \cdot F_{b} .
$$

From the analysis of Eq. (5), we can see that the axial force of the threads has a direct impact on the makeup torque, and there is a linear correspondence between them. The connector thread's contact surface's friction coefficient is about 0.08 and the thread angle is $3^{\circ}$, which allows the contact surface to produce self-locking, and there will be no relative slide due to the axial tension for the drill pile. The effect that axial force produces is similar to the effect of makeup torque; the analysis of the thread contact force under the action of axial force can be converted to the analysis of makeup torque, and subsequent analysis of torque contains the influence factors of axial force.

\subsubsection{Contact mechanical model of the joint}

The drill pipe thread is a taper thread, and the inner radius of the box joint is smaller than the outer radius of the pipe body for the radial joints at a certain point (such as tolerance or machining error), and the surface contact pressure is generated at the contact interface. A schematic diagram of the connection between the box and the pin joint is shown in Fig. 4.

Let $R_{a}$ be the inner diameter of a pin joint, $R_{b}$ the outside diameter of a pin joint (which is also the inner diameter of a box joint), and $R_{c}$ the outside diameter of a box joint, and the external pressure can be described as $P_{e}=0$. According to Eq. (3), the radial displacement of the inner surface of the box connector is expressed as

$u_{1}=\frac{R_{b} \cdot P_{\mathrm{b}}}{E} \cdot\left(\frac{R_{b}^{2}+R_{c}^{2}}{R_{c}^{2}-R_{b}^{2}+\mu}\right)$.

According to Eq. (3), the inner drilling mud pressure $P_{\mathrm{i}}=0$, and the radial displacement of the outer surface of the joint is

$u_{2}=\frac{R_{b} \cdot P_{\mathrm{b}}}{E} \cdot\left(\frac{R_{a}^{2}+R_{b}^{2}}{R_{a}^{2}-R_{b}^{2}}+\mu\right)$. 


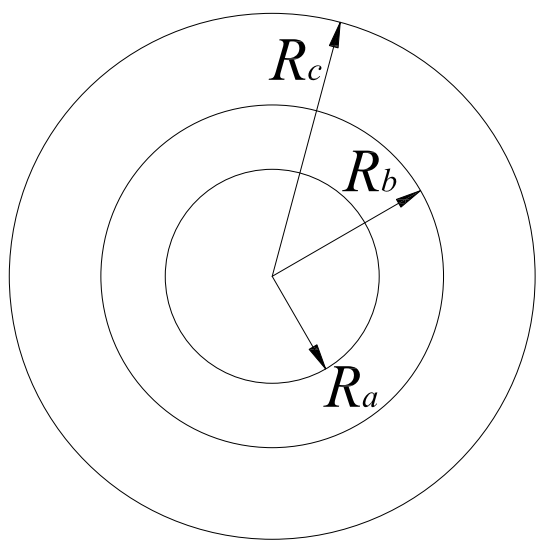

Figure 4. Connection diagram of the box and the pin joint.

Because the increment of the inner diameter of the joint and the reduction of the outer diameter of the joint is equal to the original tolerance value, the existing constraint is

$u_{1}+u_{2}=\delta$.

By combining Eqs. (6)-(8), the surface contact pressure between the pin and the box joint can be obtained by simplifying:

$$
P_{\mathrm{b}}=\frac{E \delta\left(R_{b}^{2}-R_{a}^{2}\right)\left(R_{c}^{2}-R_{b}^{2}\right)}{2 R_{b}^{3}\left(R_{c}^{2}-R_{a}^{2}\right)} .
$$

\subsubsection{The circumferential stress model of joint}

When fastening the screw, radial contact pressure is generated in external threads. From Eq. (2), the maximum axial stress occurred in the inner wall, and according to Lame's theory, the axial force and the circumferential stress generated by fastening the pin joint external thread can be expressed as

$$
\left\{\begin{array}{l}
R_{1}=R_{a} \\
R_{2}=R_{b} \\
\sigma_{\mathrm{t} 1 \cdot \max }=-\frac{R_{b}^{2} \cdot P_{\mathrm{b}}}{R_{b}^{2}-R_{a}^{2}}\left(1+\frac{R_{a}^{2}}{R_{a}^{2}}\right)=\frac{2 R_{b}^{2} \cdot P_{\mathrm{b}}}{R_{b}^{2}-R_{a}^{2}} .
\end{array}\right.
$$

A negative sign of the circumferential stress is compressive stress. For the box joint, contact pressure is uniform internal stress. From Eq. (1), the maximum circumferential stress is on the inner wall; according to Lame's theory, the axial force and the circumferential stress generated by fastening the box joint internal thread can be expressed as

$$
\left\{\begin{array}{l}
R_{1}=R_{a} \\
R_{2}=R_{b} \\
\sigma_{\mathrm{t} 2 \cdot \max }=-\frac{R_{b}^{2} \cdot P_{\mathrm{b}}}{R_{c}^{2}-R_{b}^{2}}\left(1+\frac{R_{c}^{2}}{R_{b}^{2}}\right)=\frac{R_{c}^{2}+R_{b}^{2}}{R_{b}^{2}-R_{a}^{2}} \cdot P_{\mathrm{b}}
\end{array} .\right.
$$

By inserting Eq. (9) into Eq. (11), the circumferential stress generated in the box joint internal thread can be obtained:

$\sigma_{\mathrm{t} 2 \max }=\frac{E \delta\left(R_{b}^{2}-R_{a}^{2}\right)\left(R_{b}^{2}+R_{c}^{2}\right)}{2 R_{b}^{3}\left(R_{c}^{2}-R_{a}^{2}\right)}$.

In the above formula, $\sigma_{\mathrm{t} 2}$ is the axial stress of the thread on the box joint that is produced $(\mathrm{Pa})$.

When the drill pipe is subjected to the pressure of the internal mud pressure $P_{\mathrm{i}}$, the combined body of the pin joint and the box joint is subjected to the outward expansion force, thereby causing the circumferential stress. According to Lame's theory, using the circumferential stress on the outer surface of the joint and the circumferential stress on the inner surface of the box joint to individually calculate the surface contact pressure $P_{\mathrm{c}}$, which is caused by internal pressure between box joint and a pin joint mating surface, the corresponding force is equal in magnitude and opposite in direction; thus

$$
\left\{\begin{array}{rl}
\sigma_{t i} & =\frac{R_{a}^{2} \cdot P_{\mathrm{i}}}{R_{c}^{2}-R_{a}^{2}}\left(1+\frac{R_{c}^{2}}{R_{b}^{2}}\right) \\
\sigma_{t e} & =\frac{R_{b}^{2} \cdot P_{\mathrm{c}}}{R_{c}^{2}-R_{b}^{2}}\left(1+\frac{R_{c}^{2}}{R_{b}^{2}}\right) \\
\sigma_{t i} & =\sigma_{t e}
\end{array} .\right.
$$

To complete Eq. (13), the contact pressure can be obtained under the action of mud pressure in the drill pipe,

$$
P_{\mathrm{c}}=\frac{R_{a}^{2}}{R_{b}^{2}} \cdot \frac{R_{b}^{2}-R_{c}^{2}}{R_{c}^{2}-R_{a}^{2}} \cdot P_{\mathrm{i}} .
$$

\subsection{Model and criterion of the sealing joint}

The circumferential stress obtained from the above analysis is superimposed; it is expressed as tensile stress when the outcome is positive. The following conditions must be satisfied in order to avoid leaking from drill pipe joints. Firstly, a rational stress distribution must be on the joints, which means that the sum of the axial force, makeup torque, and the contact pressure caused by the difference between the mud in the inner and outer pipe must be larger than the difference between the inner and outer pipe. Secondly, the stress distribution must be kept balanced to ensure a larger sealing area. Therefore, the relationship can be expressed as

$$
P_{\mathrm{b}}+P_{\mathrm{c}} \geq\left|P_{\mathrm{i}}-P_{e}\right| \text {. }
$$

\section{Finite-element analysis}

\subsection{Material properties of joints}

Material properties given in Table 1 are linear and isotropic as modal analysis ignores nonlinearities. Young's modulus and density for a modal analysis must be specified. 
Table 1. Material properties.

\begin{tabular}{lcccccc}
\hline Component & Materials & $\begin{array}{c}\text { Young's } \\
\text { modulus } \\
\left(\mathrm{N} \mathrm{mm}^{-2}\right)\end{array}$ & $\begin{array}{c}\text { Poisson's } \\
\text { ratio }\end{array}$ & $\begin{array}{c}\text { Tensile } \\
\text { strength } \\
(\mathrm{MPa})\end{array}$ & $\begin{array}{c}\text { Yield } \\
\text { strength } \\
(\mathrm{MPa})\end{array}$ & $\begin{array}{c}\text { Hardness } \\
(\mathrm{HB})\end{array}$ \\
\hline Box joint & $42 \mathrm{CrMo4}$ & 205000 & 0.3 & 1080 & 930 & 217 \\
Pin joint & $42 \mathrm{CrMo4}$ & 205000 & 0.3 & 1080 & 930 & 217 \\
\hline
\end{tabular}

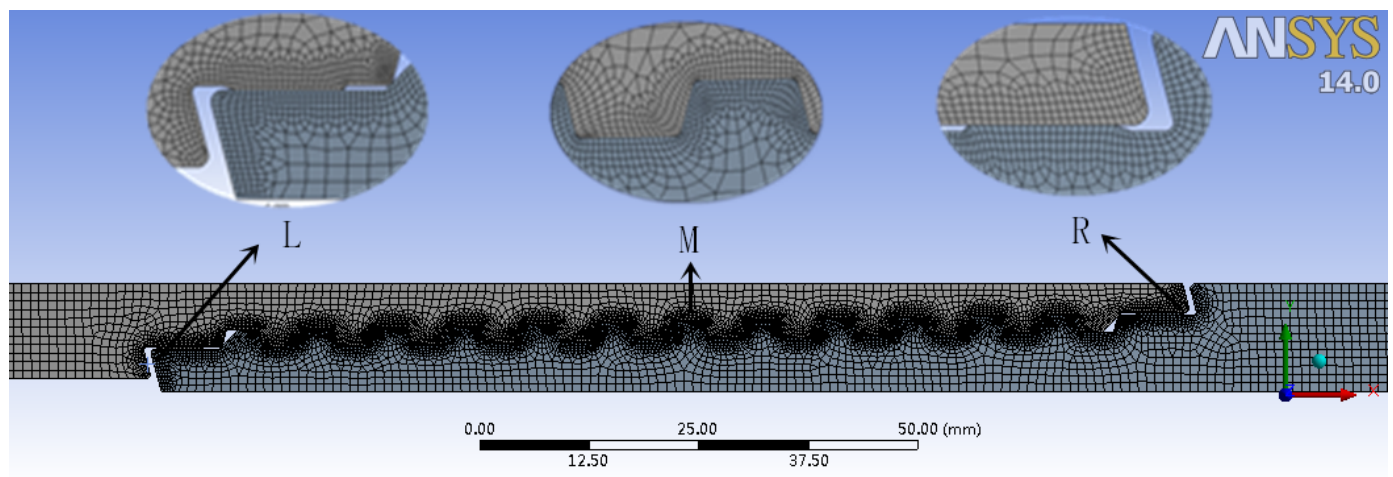

Figure 5. Finite-element model ( $\mathrm{L}$ - left shoulder; $\mathrm{M}$ - middle screw; $\mathrm{R}$ - right shoulder).

\subsection{Finite-element modelling}

A parametric 3-D model can be a better choice to comprehensively reflect the situation of the joint. Considering the smaller thread's lead angle and that the main research emphasis of this paper focuses on the relationship of the helical tooth's strain and the sealing quality, the influence of the thread's lead angle can be ignored when modelling, which makes it possible to establish a 2-D model to simulate the joint.

In this paper, the contact interference is applied to simulate the makeup state. Friction torque of each tooth buckle can be obtained through multiplying the contact pressure on the interference surface by the distance between the contact surface and the pipe centre. The equivalent makeup torque can be obtained by integrating all the friction torques of the buckle on the teeth. The value of the tooth interference of threads can be calculated on the basis of the number of turns on the buckle, as well as thread taper, pitch, tooth type angle and other parameters. Based on the API's common method of calculating the radial movement $\delta_{\mathrm{r}}$, the pin buckle to box buckle can be expressed as follows:

$\delta_{\mathrm{r}}=0.5 T \times \Delta L=0.5 T \cdot n \cdot P=0.5 T \times \frac{\theta}{360} \times P$.

\subsection{Element selection and meshing}

Solid structural steel defined as $42 \mathrm{CrMo} 4$ is used for modelling of different components, i.e. the box joint, pin box and drilling pipe body. For both the box joint and pin box,
Table 2. Interferences of contact surfaces.

\begin{tabular}{lcccc}
\hline & Addendum & $\begin{array}{c}\text { Bearing } \\
\text { surface }\end{array}$ & $\begin{array}{c}\text { Guide } \\
\text { surface }\end{array}$ & $\begin{array}{c}\text { Shoulder } \\
\text { surface }\end{array}$ \\
\hline Interference $(\mathrm{mm})$ & 0.0100 & 0.0025 & 0.0025 & 0.6000 \\
\hline
\end{tabular}

"manual contact region" contact elements are used; therefore, both of the threaded surfaces are of the same element type. Two-dimensional "manual contact region" contact elements, in combination with the command CONTACT for pin joint surface and TARGET for the box joint surface are used between the box joint and pin joint surface to simulate contact distribution.

Body-sizing meshing is used throughout in the regions of the high-stress distribution box, i.e. box joint faces and pin joint faces. Front areas of the model are meshed first and then the same meshing pattern of meshed area is swept over the volumes. The command "Refinement" is used for the meshing with $3 \times$ amplification. The FEM of the joint thread fitting is shown in Fig. 5.

\subsection{Boundary conditions and loading}

In order to eliminate the boundary effect in simulation, the pipe length in the model should be 2 times longer than the length of the drill pipe end to the thread disappearing point. The equivalent torque and axial force are applied by setting the contact interference or applying a preload. 


$$
\left\{\begin{array}{l}
\delta_{\mathrm{n} s}=\delta_{\mathrm{r}} \cdot \cos \alpha \\
\delta_{\mathrm{n} l}=\delta_{\mathrm{r}} \cdot \sin 14.5^{\circ} \\
\delta_{\mathrm{n} d}=\delta_{\mathrm{r}} \cdot \sin 14.5^{\circ}-\Delta
\end{array}\right.
$$

Through the above formulas, the amount of interference of the thread of each surface can be calculated by setting the offset to define the size of the contact between the unit and the target unit in ANSYS in a real constant offset, which is the value of the force. Using the software, the axial tension and internal pressure can be simulated in the form of uniform force, which can be loaded directly onto the threaded model. In the three different mating connector states, including finger-tight, tight state machine and state interference, the tension and the pressure of $0-300 \mathrm{kN}$ are respectively loaded onto a pair of mating threaded joints per $50 \mathrm{kN}$. The stress distribution and air tightness are studied according to the preceding model.

The $68 \mathrm{~mm}$ diameter drill pipe is mainly used in the well with the maximum depth of 2000-2500 m. The maximum axial tension and compression load is calculated at about $300 \mathrm{kN}$ on account of its weight and length of the 1 strings, which are selected as the parameters used. In addition, the data are collected with a gradient of $50 \mathrm{kN}$ to better reflect stress.

\section{Results and analysis}

\subsection{Pipe joints and its connection states}

There are 12 screw threads on the joint. Three different basic states will exist during tightening of the pipe joints. As shown in Fig. 6, for connection state $A$, the makeup torque is relatively small, resulting in a certain gap existing in the thread shoulder. In connection state $B$, the thread shoulders are in contact with each other but with no pressure generated. In connection state $C$, the thread should also be in contact and the pressure can be very large. The three different states can represent three different practical situations to describe the joint's strength and tightness.

\subsection{Stress distribution of pipe joints}

Tensile force will be exerted on the pipe while dealing with problems, while pressure will be exerted on the pipe during drilling. Based on experience with simulation and real practice, for the pipe $68 \mathrm{~mm}$ diameter, the maximum tensile stress is $250 \mathrm{kN}$, and the maximum pressure is $150 \mathrm{kN}$. Therefore, there are corresponding changes under three different connection states, with the force changes in the range of 150$250 \mathrm{kN}$. The selection of a pipe can be determined on the basis of the changes.

\subsubsection{Joint state under allowable tensile force}

When the axial tension reaches $250 \mathrm{kN}$ in the joint's fingertight connection state, the maximum contact stress of the

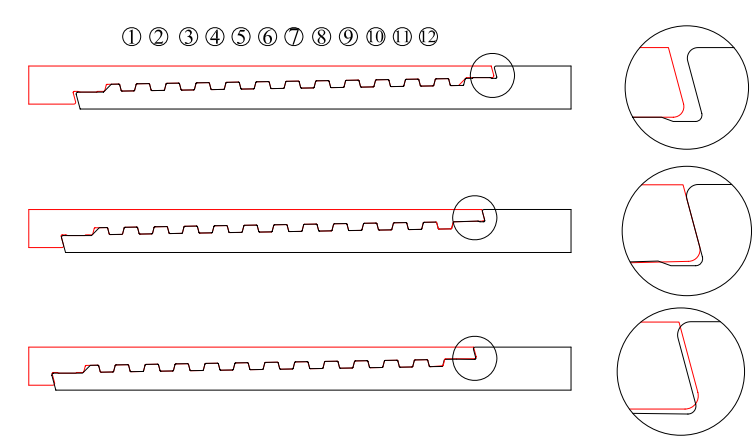

Figure 6. Connection states of the joints.

thread reaches 11.43 $\mathrm{MPa}$. The left sealing surface contact stress reaches 397.24 MPa when the drill machine is in a state that is tight but under interference. The left sealing surface contact stress reaches 397.24 MPa when the drill machine is in an interference state. In Fig. 7, it is shown that, with the increase in torque on the buckle, contact stress between the pin and the box connectors will correspondingly increase.

\subsubsection{Joint state under allowable yield force}

When axial tension reaches $150 \mathrm{kN}$ in the joint's finger-tight connection state, as shown in Fig. 8, the maximum contact stress of the thread reaches $6.13 \mathrm{MPa}$. The left sealing surface contact stress reaches $488.6 \mathrm{MPa}$ when the drill machine is in a state that is tight but under interference. The left sealing surface contact stress reaches $931.6 \mathrm{MPa}$ when the drill machine is in an interference state. Similarly, it is shown that, with the increase in torque on the buckle, contact stress between the pin and the box connectors will also correspondingly increase.

\subsubsection{Stress change principle with three different connection types}

As shown in Fig. 9, in comparison with the influence axial load, the influence of the connection type is more obvious. This shows that the makeup torque is the key factor that determines the sealing quality and joint strength. When the thread is in a finger-tight state, the thread engagement is unstable, especially when tensile force is exerted. When the machine changes gradually to the interference state from the tight state, the contact stress is larger on both ends of the shoulder but the contact stress in the middle of each thread is generally relatively stable.

When the drill bit is in connection mode $A$, too much strain will generate on the thread, resulting in structural damage after axial tension reaches $251 \mathrm{kN}$. When in mode $B$, the contact stress for each part of the joint is always within the stress limits, but with the increase in the makeup torque, the contact stress of the sealing surface will further increase. When in mode $C$, and the stress exceeds $150 \mathrm{kN}$, the local stress 


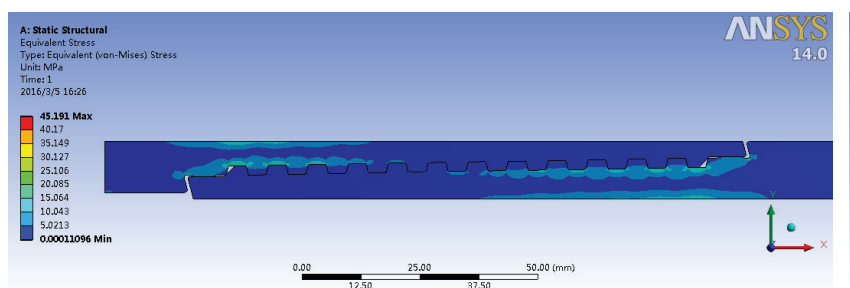

(a)

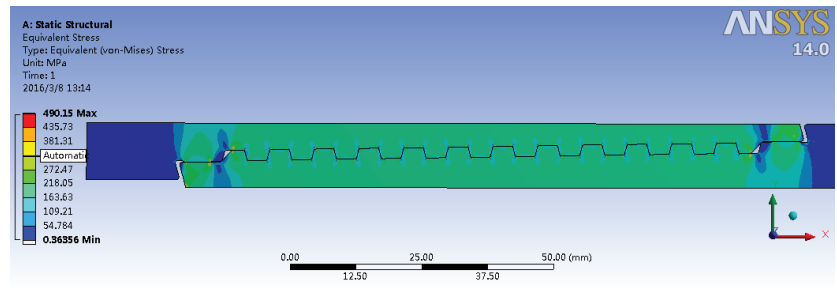

(c)

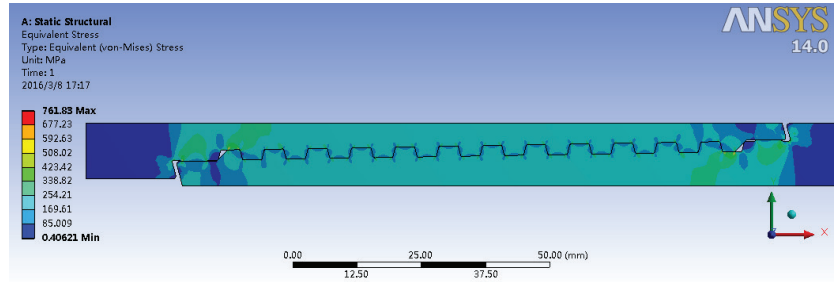

(e)

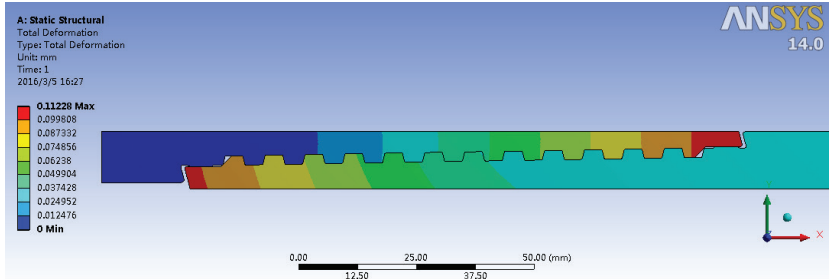

(b)

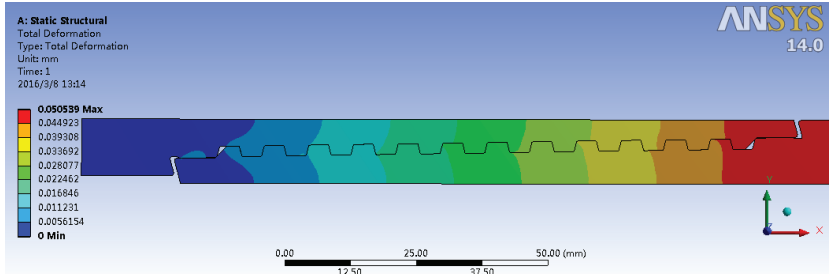

(d)

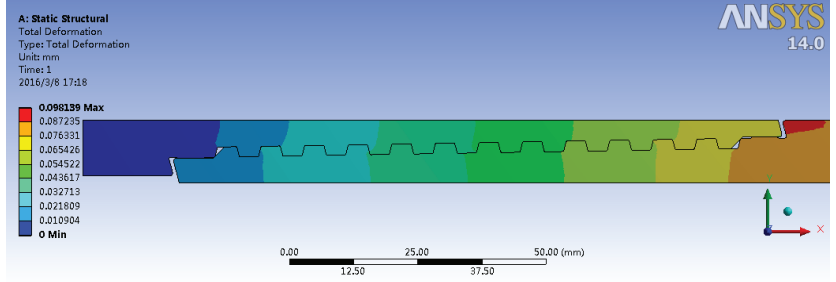

(f)

Figure 7. Joint stress and strain under allowable tensile force: (a) joint stress in state $A$, (b) joint strain in state $A$, (c) joint stress in state $B$, (d) joint strain in state $B$, (e) joint stress in state $C$ and (f) joint strain in state $C$.

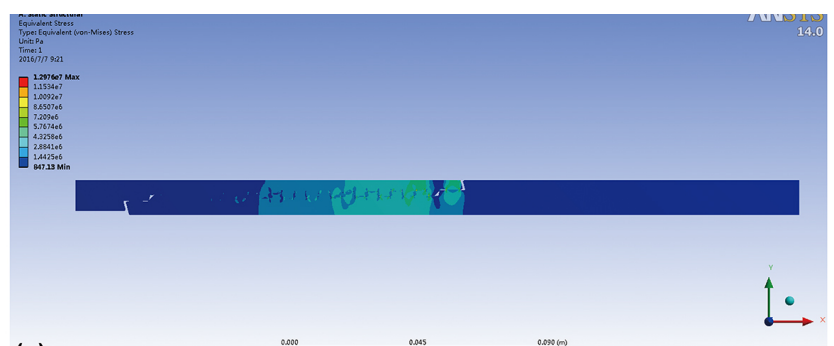

(a)

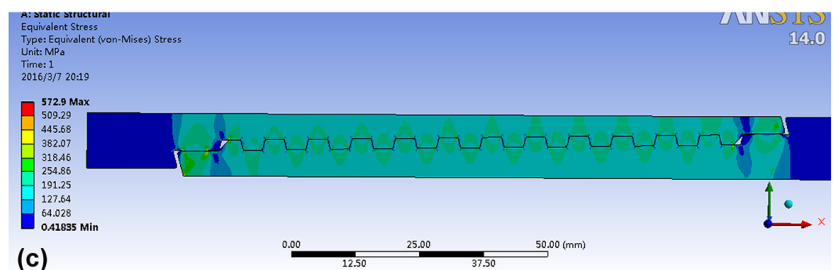

(c)



(e)

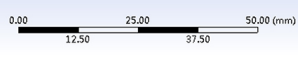

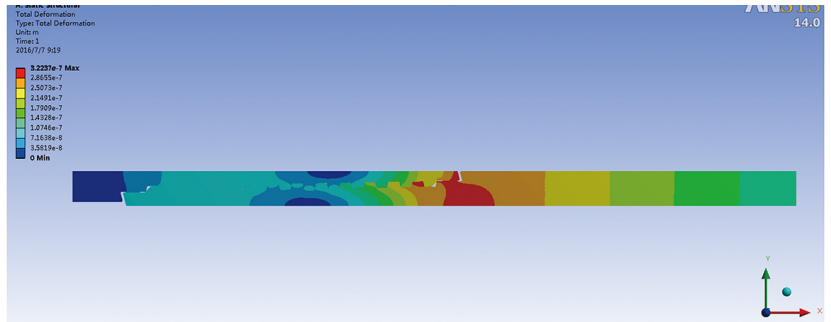

(b)
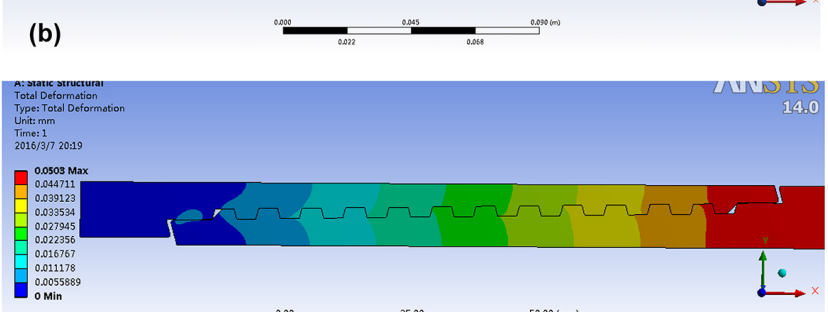

(d)
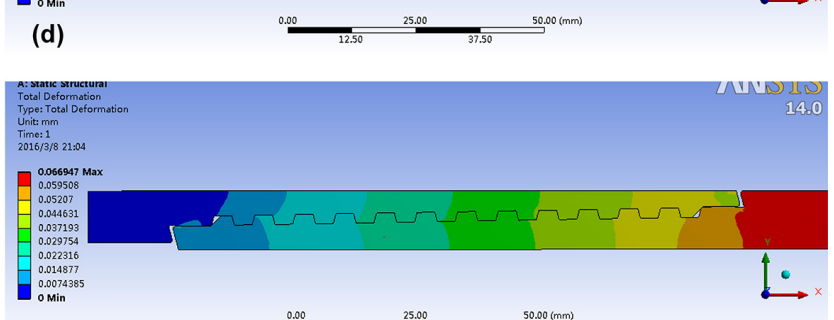

(f)

Figure 8. Joint stress and strain under allowable tension force: (a) joint stress in state $A$, (b) joint strain in state $A$, (c) joint stress in state $B$, (d) joint strain in state $B$, (e) joint stress in state $C$ and (f) joint strain in state $C$. 
(a)

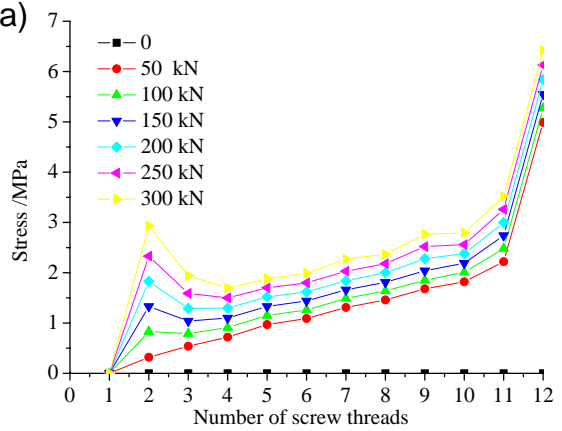

(c)

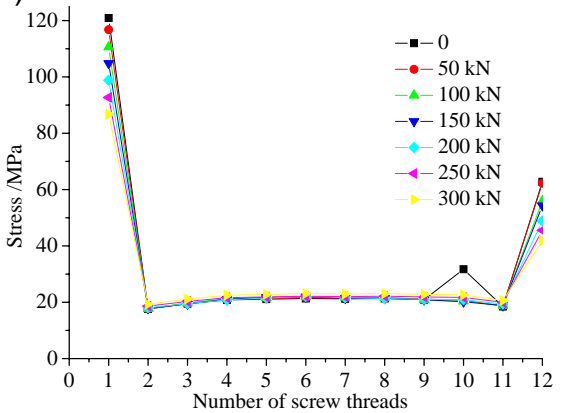

(e)

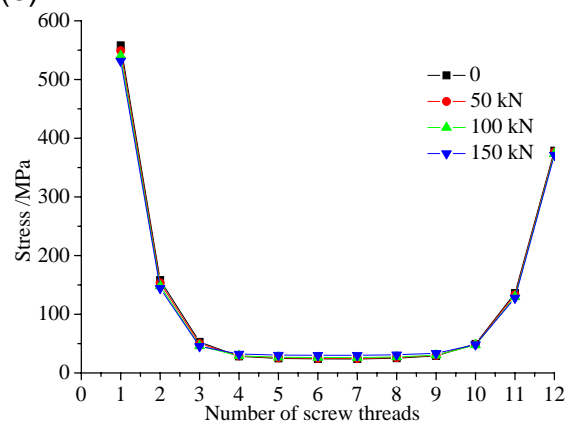

(b)

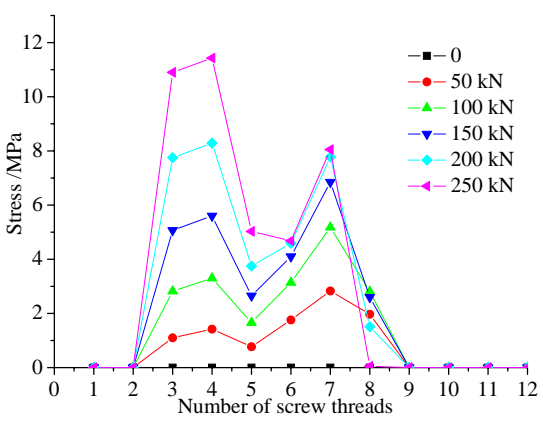

(d)

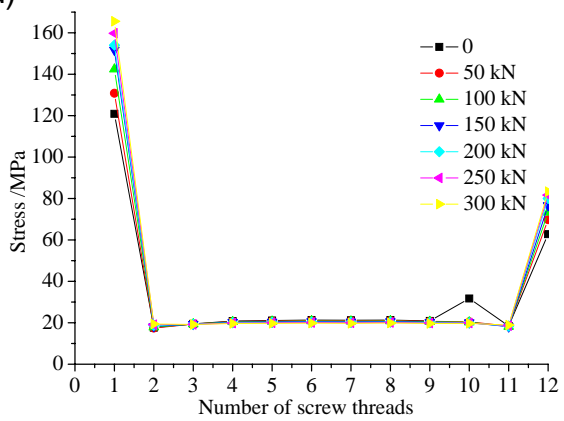

(f)

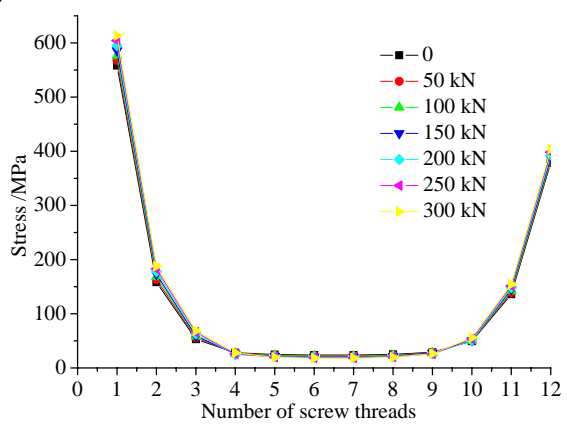

Figure 9. Stress change principle with different connection types: (a) tension stress in state $A$, (b) tensile stress in state $A$, (c) tension stress in state $B$, (d) tensile stress in state $B$, (e) tension stress in state $C$ and (f) tensile stress in state $C$.

will exceed the yield limit. The joints' carrying capacity will decrease during the loading process because the initial stress is too large, which causes the bearing capacity of the joint on the axial pressure to be less than the axial tension. At the same time, the thread will produce plastic strain, affecting the airtightness. In addition, the overall strength of the joints will also decrease under the dynamic loading.

All in all, the interference fit between the threads significantly increases the overall strength of the joint effect, but the contact pressure is not always better. When taking the limitations of the material itself into account, the following condition must be greater than the pressure difference inside and outside the drill pipe, which additionally should remain stable during operation.

\subsection{Calculation of the premium makeup torque}

\section{The scale model}

The law of thread stress changing in different axial loading is found through the model simulation mentioned above. It is concluded that we can apparently get more data through simulation experiments through increasing the number of teeth. Some errors exist between the actual situation and the simulation. Therefore, the scale model shown in Fig. 10 is introduced again to calculate the makeup torque.

Model exposure settings, mesh, interference, etc. are set with reference to the original model. The working environment is fairly complex during drilling. A sudden increase in torque will probably occur if there is friction between the drill pipe and the borehole wall or if faults occur. In this case, the up-torque is too large, which will result in the initial contact stress exceeding the limit, causing plastic defor- 


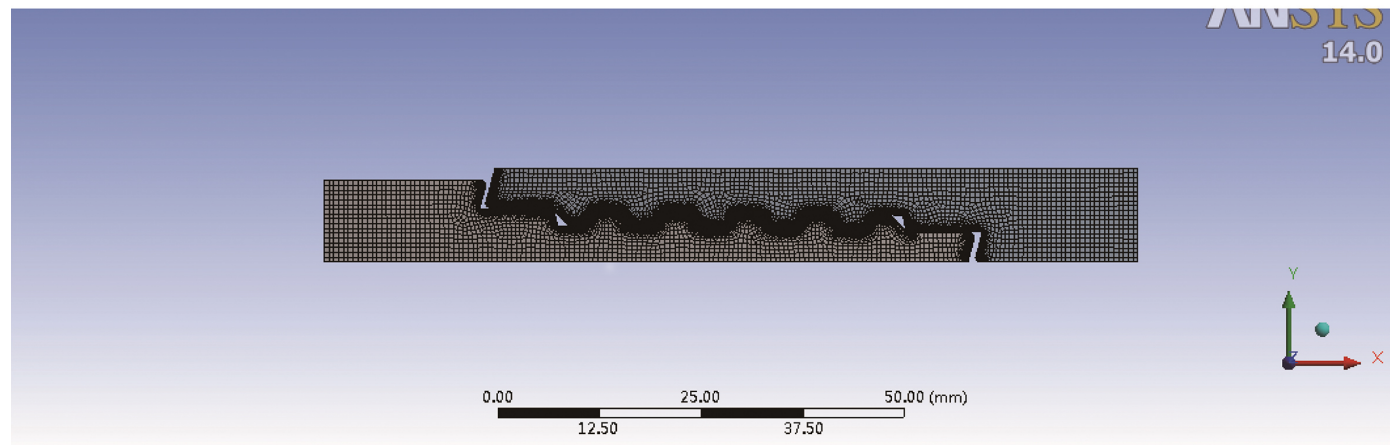

Figure 10. The scale model.
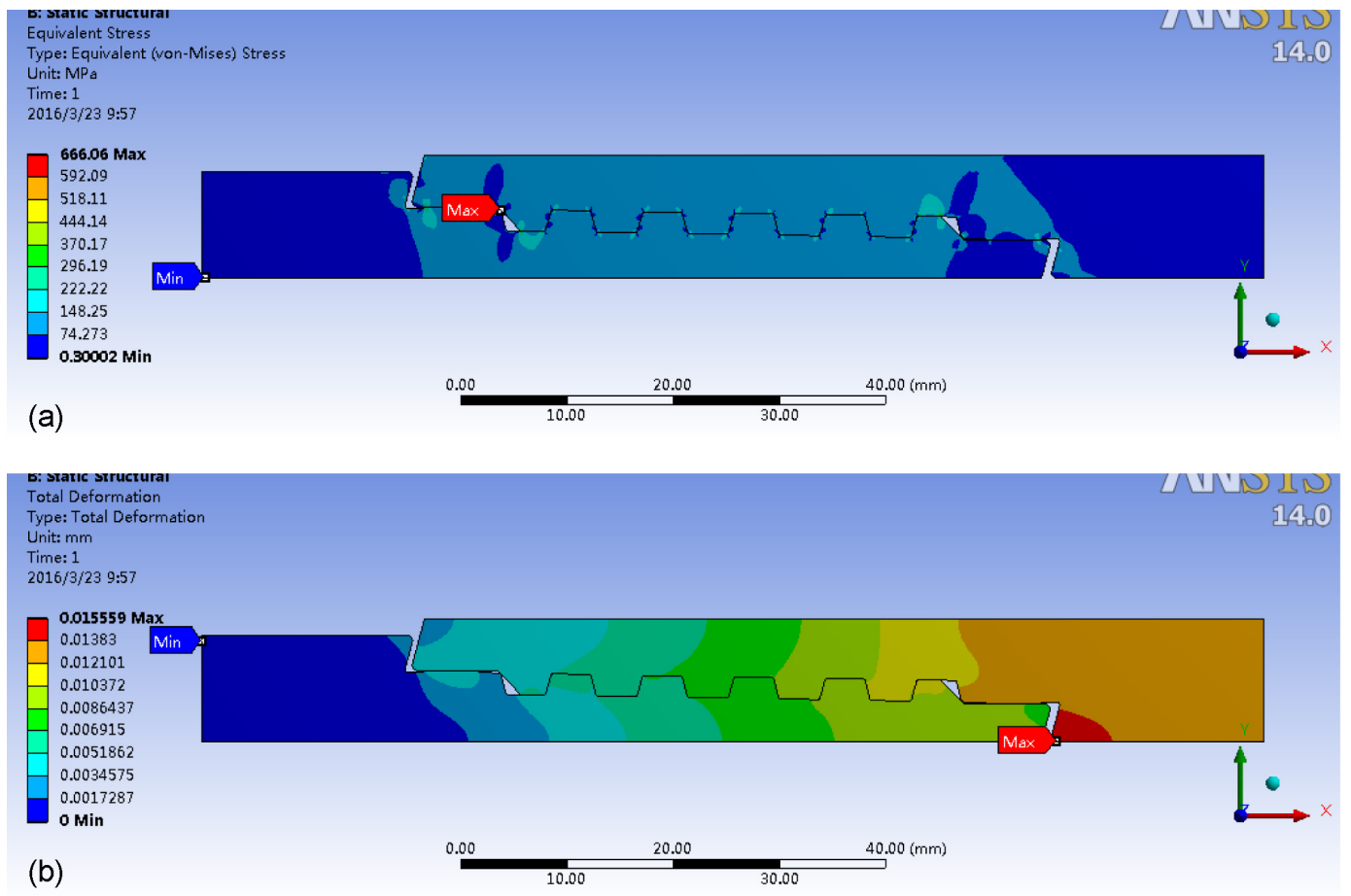

Figure 11. Connection state under optimum makeup torque: (a) stress under optimum makeup torque and (b) strain under optimum makeup torque.

mation and affecting the joint's airtightness. Therefore, the safety coefficient should be introduced to provide a safe elastic stress range. In order to get the best deduction, the reference value for the maximum contact stress safety factor is given as $620 \mathrm{MPa}$, whereby the amount of thread interference can be drawn in the radial direction. Interferences of the contact surfaces are shown in Table 2 . The values of interferences of the axial and the bearing surfaces can be calculated through the radial values. Therefore, we can get the distribution of the stress and strain under optimum makeup torque, which are shown in Fig. 11. We can see the stress distribution has more uniform than aforementioned states, and it must be kept balanced to ensure a larger sealing area.
The stress distribution is mostly influenced by torque, which determines the stress magnitudes on different joint contact surfaces, affecting the strength of the connection and sealing joints. The torque is obtained from the values of friction force and centre distance in simulation, and it is accumulated from three different components: the shoulder, sealing surface and screw thread. As shown in Table 3, the makeup torque will reach $3320.66 \mathrm{~N} \mathrm{~m}^{-1}$ when in the premium state, where the torque between the buckle teeth is $2560.32 \mathrm{~N} \mathrm{~m}^{-1}$, and the torque between the sealing surface and the shoulder is $760.34 \mathrm{~N} \mathrm{~m}^{-1}$. The torque in each case takes up 77 and $23 \%$ of the overall makeup torque, respectively, which means that 
Table 3. Composition of the optimum makeup torque.

\begin{tabular}{|c|c|c|c|c|c|}
\hline Items & Position & $\begin{array}{r}\text { Friction } \\
\text { force } \\
(\mathrm{kN})\end{array}$ & $\begin{array}{c}\text { Centre } \\
\text { distance } \\
(\mathrm{mm})\end{array}$ & $\begin{array}{r}\text { Torque } \\
\left(\mathrm{N} \mathrm{m}^{-1}\right)\end{array}$ & $\begin{array}{c}\text { Total } \\
\text { torque } \\
\left(\mathrm{N} \mathrm{m}^{-1}\right)\end{array}$ \\
\hline Left shoulder & Contact surfaces & 2.88 & 32.10 & 92.45 & \\
\hline Left sealing surface & Contact surfaces & 14.65 & 27.30 & 399.95 & 492.40 \\
\hline \multirow{3}{*}{ 1st screw thread } & Addendum & 5.68 & 29.50 & 167.56 & \multirow{3}{*}{469.97} \\
\hline & Dedendum & 8.55 & 27.62 & 236.15 & \\
\hline & Bearing surface & 2.32 & 28.56 & 66.26 & \\
\hline \multirow{3}{*}{ 2nd screw thread } & Addendum & 5.05 & 29.74 & 150.19 & \multirow{3}{*}{499.76} \\
\hline & Dedendum & 8.34 & 27.86 & 232.35 & \\
\hline & Bearing surface & 4.07 & 28.80 & 117.22 & \\
\hline \multirow{3}{*}{ 3rd screw thread } & Addendum & 5.21 & 29.98 & 156.20 & \multirow{3}{*}{515.15} \\
\hline & Dedendum & 8.32 & 28.10 & 233.79 & \\
\hline & Bearing surface & 4.31 & 29.04 & 125.16 & \\
\hline \multirow{3}{*}{ 4th screw thread } & Addendum & 5.18 & 30.22 & 156.54 & \multirow{3}{*}{526.60} \\
\hline & Dedendum & 8.45 & 28.34 & 239.47 & \\
\hline & Bearing surface & 4.46 & 29.28 & 130.59 & \\
\hline \multirow{3}{*}{ 5th screw thread } & Addendum & 5.47 & 30.46 & 166.62 & \multirow{3}{*}{548.84} \\
\hline & Dedendum & 7.92 & 28.58 & 226.35 & \\
\hline & Bearing surface & 5.28 & 29.52 & 155.87 & \\
\hline \multirow{3}{*}{$\begin{array}{l}\text { Right sealing surface } \\
\text { Left shoulder }\end{array}$} & Contact surfaces & 2.79 & 30.70 & 85.65 & \multirow{2}{*}{267.94} \\
\hline & Contact surfaces & 4.94 & 36.90 & 182.29 & \\
\hline & & & & \multicolumn{2}{|c|}{ Total: $3320.66 \mathrm{Nm}$} \\
\hline
\end{tabular}

it plays a significant role in keeping the sealing quality of the pipe.

\section{Conclusions}

1. The connection type - $A, B$, and $C$ - has a greater effect on the contact stress than the axial loading's effect, which means the makeup torque is the key factor that determines the joint's strength and its sealing quality.

2. The joints' double shoulders can significantly boost the thread's overall stability because the shoulder reduces the phenomenon of stress concentration and takes a part of axial force, which enhances the thread's overall sealing quality and axial strength.
3. With the increase in the makeup torque, the maximum contact stress gradually changes from the thread's teeth to the shoulders on both ends, which enhances the overall sealing quality but weakens the structural strength. Plastic deformation occurs on some of the thread, which exceeds the allowable load.

4. When the makeup torque reaches up to $3320.66 \mathrm{Nm}$, the contact stress of the sealing shoulder is greater than the pressure difference between the inner and outer pipe. The even distribution of the joint thread's stress contributes to the pipe joint's sealing and overall strength, which provides a good reference for selecting the parameters of the drilling tool's makeup. 


\section{Appendix A}

Table A1. Nomenclature.

\begin{tabular}{ll}
\hline$\sigma_{\mathrm{r}}$ & radial stress, Pa \\
$\sigma_{t}$ & circumstantial stress, $\mathrm{Pa}$ \\
$R_{1}, R_{2}$ & the inner and outer radius, respectively, $\mathrm{m}$ \\
$R$ & radius at any point, $\mathrm{m}$ \\
$E$ & elastic modulus, $\mathrm{Pa}$ \\
$\mu$ & Poisson's ratio \\
$u$ & radial displacement when the radius is $R, \mathrm{~m}$ \\
$P_{\mathrm{i}}$ & drilling mud pressure from inner drilling pipe, $\mathrm{Pa}$ \\
$P_{e}$ & drilling mud pressure from outer drilling pipe, $\mathrm{Pa}$ \\
$f$ & friction force produced by axial force, $\mathrm{N}$ \\
$\mu$ & friction coefficient of screw thread \\
$N$ & supporting force on screw thread face, $\mathrm{N}$ \\
$F_{\mathrm{f}}$ & tangential force of the thread, $\mathrm{N}$ \\
$F_{b}$ & component force of drill pipe, $\mathrm{N}$ \\
$\beta$ & helix angle, rad \\
$K$ & proportional coefficient \\
$u_{1}$ & radial displacement of the inner surface of the box joint, $\mathrm{m}$ \\
$u_{2}$ & radial displacement of the outer surface of the pin joint, $\mathrm{m}$ \\
$R_{a}$ & inner diameter of the pin joint, $\mathrm{m}$ \\
$R_{b}$ & outer diameter of the pin joint, $\mathrm{m}$ \\
$R_{C}$ & outer diameter of the box joint, $\mathrm{m}$ \\
$P_{\mathrm{b}}$ & radial surface contact pressure between pin and box joints, $\mathrm{N}$ \\
$\sigma_{\mathrm{t} 1}$ & axial stress of the thread on the pin joint produced, Pa \\
$\sigma_{\mathrm{t} 2}$ & axial stress of the thread on the box joint produced, Pa \\
$P_{\mathrm{c}}$ & contact pressure produced by the inner drilling mud pressure, $\mathrm{N}$ \\
$P_{\mathrm{i}}$ & mud pressure inside drill pipe, $\mathrm{N}$ \\
$\sigma_{t i}$ & circumferential stress in the inner surface of the box joint, $\mathrm{Pa}$ \\
$\sigma_{t e}$ & circumferential stress in the outer surface of the pin joint, $\mathrm{Pa}$ \\
$\delta_{\mathrm{r}}$ & radial movement of the pin buckle to box buckle, $\mathrm{m}$ \\
$T$ & thread taper \\
$\Delta L$ & axial movement of the pin buckle to box buckle, $\mathrm{m}$ \\
$n$ & number of button turns on compact machine \\
$P$ & thread pitch, $\mathrm{m}$ \\
$\delta_{\mathrm{n} s}$ & buckle rotation angle, rad \\
$\delta_{\mathrm{n} l}$ & normal interference between addendum and dedendum, $\mathrm{m}$ \\
\hline & normal interference of the bearing surface, $\mathrm{m}$ \\
\hline & original gap of the guide surface, $\mathrm{m}$ \\
\hline
\end{tabular}


Competing interests. The authors declare that they have no conflict of interest.

Acknowledgements. This work is supported by the National Natural Science Foundation of China (no. 41572360, 11472249), the National Key Technology Support Program of China (no. 2015BAD20B02) and the Fundamental Research Funds for the Central Universities (no. 292015061). We thank the researchers for their excellent work, which was of great help for our academic study.

Edited by: D. D. Ganji

Reviewed by: three anonymous referees

\section{References}

American Petroleum Institute: API Recommended Practise 7G (RP 7G), Recommended practice for drill stem design and operating limits, 15th Edn., Washington, 1995.

Baryshnikov, A. and Baragetti, S.: Rotary shouldered thread connections: Working limits under combined static loading, J. Mech. Design, 123, 456-463, 2001.

Gong, W.: Relation of the sealing ability of casing threads to connenction stress, China Petrol. Mach., 23, 27-36, 1995.

Griffin, R. C., Kamruzzaman, S., and Strickler, R. D.: Casing drilling drill collars eliminate down hole failures, in: Offshore technology conference, OTC 16596, 3-6 May 2004, Houston, Texas, 1-7, 2004.

Li, F., Hu, J., Li, Y., Hang, L., and Wang, X.: Development and application of $\varnothing 73 \mathrm{~mm}$ direct-connected drill pipe, China Petrol. Mach., 39, 57-60, 2011.
Li, J., Xu, Y., and Xu, J.: Fatigue analysis of mining tool joint based on ANSYS, Coal Mine Mach., 35, 74-76, 2014.

Santus, C., Bertini, L., and Beghini, M.: Torsional strength comparison between two assembling techniques for aluminium drill pipe to steel tool joint connection, Int. J. Pressure Vessels Piping, 86, 177-186, 2009.

Shahani, A. R. and Sharifi, S. M. H.: Contact stress analysis and calculation of stress concentration factors at the tool joint of a drill pipe, Mater. Design, 30, 3615-3621, 2009.

Shi, J., Liu, X., Ma, J., Wang, F. H., and Ma, L.: Application of nonAPI drilling tools in slim hole horizontal well, Oil Drill. Product. Technol., 36, 120-122, 2014.

Tafreshi, A. and Dover, W. D.: Stress analysis of drill string threaded connections using finite element method, Int. J. Fatigue, 15, 429438, 1993.

Wang, X., Shen, Z., Wang, J., and Lin, K.: Study on the Makeup Torque Constitutes and Seal Integrity of Tubing and Casing Premium Connection, Oil Field Equip., 39, 45-50, 2010.

Zhang, K., Li, M., and Liu, X.: Advances of slim-hole cementing technologies at home and abroad, Drill. Product. Technol., 38, 23-26, 2015.

Zhang, Y., Shi, Z., Tian, D., Gong, C., and Peng, L.: Finite element analysis and improved design for taper trapezium joint threads of high-strength drilling rod with big hole, J. China Coal Soc., 35, 1219-1223, 2010.

Zhou, X.: Simulation analysis of petroleum premium casing connection, China University of Petroleum, Qingdao, 2009.

Zhu, X., Dong, L., and Tong, H.: Failure analysis and solution studies on drill pipe thread gluing at the exit side of horizontal directional drilling, Eng. Failure Anal., 33, 251-264, 2013.

Zhuang, Y., Lu, X., Gao, L., and Yuan, P.: Force Analysis and Fastening Turns Optimization of Airtight Drill Pipe Joint, China Petrol. Mach., 43, 30-35, 2015. 